\title{
Analysis of Carotenoids in 25 Indigenous Korean Coral Extracts
}

\author{
Sang Min Kim · Suk-Woo Kang $\cdot$ Eun A Lee $\cdot$ Eun-Kyoung Seo $\cdot$ Jun-Im Song \\ - Cheol-Ho Pan*
}

Received: 31 July 2012 / Accepted: 7 December 2012 / Published Online: 31 March 2013

(C) The Korean Society for Applied Biological Chemistry 2013

\begin{abstract}
In this study, methanol extracts from 25 indigenous Korean corals were prepared and their carotenoid constituents were analyzed by high-performance liquid chromatographyatmospheric pressure chemical ionization-mass spectrometry (HPLC-APCI-MS). Among them, extracts from nine species showed detectable peaks in the HPLC chromatogram at $450 \mathrm{~nm}$ and the ultraviolet/visible spectra exhibiting carotenoid-specific characteristics were chosen. The mass data of carotenoid peaks revealed that only peridinin could be identified based on literature comparison and suggested the potential presence of novel carotenoid structures. This is the first reported investigation of indigenous Korean coral carotenoids and further work is needed to explore the carotenoids and their potential roles in the ecosystem of indigenous Korean corals.
\end{abstract}

Keywords carotenoid $\cdot$ coral $\cdot$ high-performance liquid chromatography-atmospheric pressure chemical ionization-mass spectrometry $\cdot$ peridinin $\cdot$ ultraviolet/visible spectrum

S. M. Kim · S.-W. Kang $\cdot$ C.-H. Pan

Functional Food Center, Korea Institute of Science and Technology, Gangneung 210-340, Republic of Korea

E. A Lee

Institute of Eco-Science, Ewha Womans University, Seoul 120-750, Republic of Korea

E.-K. Seo

College of Pharmacy, Ewha Womans University 120-750, Republic of Korea

J.-I. Song

Department of Life Sciences, Ewha Womans University 120-750, Republic of Korea

*Corresponding author (C.-H. Pan: cheolpan@gmail.com)

\section{Introduction}

Corals are marine animals in the class Anthozoa; they typically live in compact colonies of many identical individuals and secrete calcium carbonate to form a hard skeleton, referred to as a coral reef (Osinga et al., 2011). Coral reefs are among the largest and most diverse ecological communities on the planet and have high economic value as a source of food and natural products (Osinga et al., 2011). Most corals obtain the majority of their energy and nutrients from photosynthetic unicellular algae, called zooxanthellae, of the genus Symbiodinium, that live within the coral's tissue (Apprill et al., 2007). The algae benefit from a safe place to live and consume the polyp's carbon dioxide and nitrogenous waste to survive. Recently, coral pigments have been the subject of interest in relation to their significance in coral bleaching, a phenomenon defined as the loss of color of corals (Venn et al., 2006). The coral symbiont pigments, including chlorophyll $a$, peridinin, chlorophyll $c_{2}$, diadinoxanthin, diatoxanthin, and $\beta$-carotene, are known to play a role not only as light harvesting components for photosynthesis but also in protecting components from high irradiance (Hochberg et al., 2006). Apprill et al. (2007) reported that visibly healthy corals exhibit variable pigment concentrations and symbiont phenotypes. Coral bleaching occurs as a result of the elimination of symbiotic algal cells or the degradation of algal pigments. Bleaching is triggered by a range of environmental stressors, including temperature extremes and high irradiance, and causes significant impact on the marine ecosystem. There have been numerous studies about environmental effects on symbiont pigment profiles in corals (Mydlarz et al., 2010). In Korea, several coral species have been reported in faunal studies from the sea area off the eastern and southern coasts of Korea (Song and Lee, 1998) and, in particular, the sea area off Jeju Island, Korea, shows the highest variety of coral species (Kang et al., 2005). However, taxonomical studies have been the major focus of previous research and few studies have been reported on the chemical constituents of Korean indigenous corals (Seo et al., 1996; Bae et al., 2000). 
The major role of carotenoids in corals is the protection of the photosynthetic apparatus of the zooxanthellae from irreversible light-induced photoinhibition that may lead to the loss or expulsion of the algal symbiont from corals (Venn et al., 2006). Thus, understanding of carotenoid pigment profiles in coral species are highly related with the symbiont algal species and the growth of corals. However, those studies have not yet been carried out on Korean indigenous corals. The purpose of this investigation was to screen major carotenoids from Korean indigenous corals and obtain schematic understanding of carotenoid profiles. For that, 25 corals were collected from the sea off the coast of Jeju island and their methanolic extracts were prepared. In addition, carotenoids pigment profiles were explored by high-performance liquid chromatography/photodiode array detector/atmospheric pressure chemical ionization-mass spectrometry (HPLC-PADAPCI-MS) and compared with literature.

\section{Materials and Methods}

Collection of samples. Twenty-five coral species were collected from Munseom, Beomseom, and Supseom, Jeju Island, and from
Geokumdo between November 2008 and July 2010 by SCUBA diving, and were identified by Prof. Jun-Im Song (Korea Coral Resources Bank; Table 1). Among them, 24 species belonged in a class Anthozoa and a phylum Cnidaria, and one species, Herdmania momus, was from subphylum Urochordata of the phylum Chordata. Voucher specimens with barcode numbers have been deposited at the Korea Coral Resources Bank, Ewha Womans University.

Extraction. Each marine organism collected was quickly washed with cold water to remove salt contained in its body. After washing the sample, its whole body was measured (wet weight) and ground. The ground sample was suspended in methanol $(\mathrm{MeOH})$ (three times the volume of the ground sample), sonicated for $2 \mathrm{~h}$ at room temperature, and then extracted for $20 \mathrm{~h}$ at room temperature, finishing with the third sonication treatment for $1 \mathrm{~h}$. The extracted sample was filtered and evaporated in vacuo, to afford a methanol-soluble extract. Each extract was further freezedried and weighed (to $10 \mathrm{mg}$ ) in an amber wide crimp top vial with a barcode number to produce the standard marine organism extract for aliquotting (Table 1).

Carotenoid analysis. HPLC-APCI-MS analysis was performed with the extract solutions at $10 \mathrm{mg} / \mathrm{mL}$ in ethanol using a Varian

Table 1 Indigenous Korean coral extracts

\begin{tabular}{|c|c|c|c|c|c|}
\hline Species name & Barcode No. ${ }^{1)}$ & Family name & Wet weight $(\mathrm{g})^{2)}$ & Extract weight $(\mathrm{g})^{3)}$ & $\begin{array}{c}\text { Extraction } \\
\text { efficiency }(\%)^{4)}\end{array}$ \\
\hline Scleronephthya gracillimum & EWZS1909 & \multirow{8}{*}{ Nephtheidae } & 282 & 5.28 & 1.87 \\
\hline Umbellulifera spiculosa & EWZS2881 & & 1200 & 31.37 & 2.61 \\
\hline Dendronephthya gigantea & EWZS1911 & & 713 & 12.32 & 1.73 \\
\hline Dendronephthya suensoni & EWZS2337 & & 1000 & 25.09 & 2.51 \\
\hline Dendronephthya mollis & KCRB87 & & 780 & 12.96 & 1.66 \\
\hline Dendronephthya putteri & EWZS2331 & & 613 & 9.65 & 1.57 \\
\hline Dendronephthya spinulosa & KCRB86 & & 1150 & 21.05 & 1.83 \\
\hline Dendronephthya castanea & EWZS2313 & & 1500 & 26.26 & 1.75 \\
\hline Acalycigorgia grandiflora & KCRB88 & \multirow[t]{2}{*}{ Acanthogorgiidae } & 640 & 14.22 & 2.22 \\
\hline Euplexaura crassa & KCRB89 & & 700 & 10.77 & 1.54 \\
\hline Bebryce thomsoni & KCRB94 & \multirow{6}{*}{ Plexauridae } & 237 & 4.39 & 1.85 \\
\hline Calicogorgia granulosa & EWZS2343 & & 1000 & 20.62 & 2.06 \\
\hline Astrogorgia sp. & EWZS3003 & & 1500 & 27.77 & 1.85 \\
\hline Villogorgia antillarum & KCRB93 & & 137 & 1.85 & 1.35 \\
\hline Plexauroides praelonga & EWZS2325 & & 1000 & 8.94 & 0.89 \\
\hline Anthoplexaura dimorpha & EWZS3002 & & 2300 & 34.95 & 1.52 \\
\hline Entacmaea quadricolor & EWZS3006 & Actiniidae & 600 & 27.52 & 4.59 \\
\hline Nemanthus nitidus & EWZS3009 & Nemanthidae & 2200 & 19.80 & 0.90 \\
\hline Montipora trabeculata & EWZS3005 & Acroporidae & 900 & 10.53 & 1.17 \\
\hline Psammocora profundacella & EWZS3007 & Thamnasteriidae & 2100 & 20.09 & 0.96 \\
\hline Alveopora japonica & EWZS3008 & Poritidae & 2700 & 31.10 & 1.15 \\
\hline Myriopathes japonica & EWZS3004 & \multirow{2}{*}{ Myriopathidae } & 900 & 24.27 & 2.70 \\
\hline Myriopathes ulex & KCRB95 & & 337 & 9.17 & 2.72 \\
\hline Palythoa sp. & KCRB91 & Sphenopidae & 510 & 15.50 & 3.04 \\
\hline Herdmania momus & KCRB90 & Pleurogona & 1200 & 31.09 & 2.59 \\
\hline
\end{tabular}

${ }^{1)}$ Barcode number refers to the sample number of voucher specimens deposited at the Korea Coral Resources Bank, Ewha Womans University.

${ }^{2)}$ Wet weight of the harvested coral sample.

${ }^{3)}$ Extract weight after extraction of whole harvested coral sample with methanol and freeze-drying.

${ }^{4)}$ (Weight of extract/Wet weight of sample) $\times 100$ 
HPLC-hyphenated MS system (USA) as described in our previous work with slight modifications (Kim et al., 2012). Sample (20 $\mu \mathrm{L})$ was injected for each experiment and the separation was carried out with an YMC carotenoid column $(250 \mathrm{~mm} \times 4.6 \mathrm{~mm}$ i.d. with a $3 \mu \mathrm{m}$ particle size; Waters, USA). The mobile phase consisted of methanol/tert-butyl-methyl ether (10:90, v/v, Solvent A) and methanol/water $(95: 5, \mathrm{v} / \mathrm{v}$, Solvent B) with a flow rate of $1 \mathrm{~mL} /$ min at $40^{\circ} \mathrm{C}$. In the gradient condition, Solvent $\mathrm{A}$ was increased to $50 \%$ over $20 \mathrm{~min}$ after $0 \%$ solvent $\mathrm{A}$ for an initial $10 \mathrm{~min}$ and then increased to $90 \%$ over $10 \mathrm{~min}$ and kept for $10 \mathrm{~min}$. The chromatograms were assessed at $450 \mathrm{~nm}$ for carotenoids. Mass spectral data were acquired from $m / z$ 200-1000 with APCI ion source (positive mode) under the following conditions: 12 psi of drying gas at $150^{\circ} \mathrm{C}, 55 \mathrm{psi}$ of nebulizing gas $\left(\mathrm{N}_{2}\right), 18$ psi of vaporizer gas pressure, a corona current of $5 \mu \mathrm{A}$, and a housing temperature of $50^{\circ} \mathrm{C}$. The analytical data were processed by using Varian MS Workstation software (ver. 6.9; USA). The putative carotenoid peaks showing $\lambda_{\max }$ peaks around $450 \mathrm{~nm}$ were selected in the HPLC chromatogram at $445 \mathrm{~nm}$ and their UV/visible spectra were acquired at the range of $250-700 \mathrm{~nm}$ by photodiode array detector (PDA). MS spectra of the putative carotenoid peaks were obtained and compared with literature data.

\section{Results and Discussion}

HPLC/PAD/APCI-MS analysis was applied to obtain carotenoid pigment profiles from coral extracts and identify major carotenoids since this analytical method has been found to be one of the most powerful techniques for the rapid identification of natural products, especially carotenoid compounds without purification step (Maoka et al., 2002). Even though it is difficult to identify the carotenoid only with APCI-MS spectral data, HPLC/ultraviolet (UV)-visible absorption spectrometry by PAD can give the chromophore information of the separated carotenoids which can not be provided from APCI-MS. In the result, the Korean indigenous coral species showed $0.89-4.59 \%$ extraction efficiency of wet sample with the methanol as solvent. Among 25 coral extracts, nine extracts, from Scleronephthya gracillimun, Calicogorgia granulosa, Astrogorgia sp., Anthoplexaura dimorpha, Entacmaea quadricolor, Montipora trabeculata, Psammocora profundacella, Alveopora japonica, and Palythoa sp., showed distinguishable peaks in the HPLC chromatograms at $450 \mathrm{~nm}$ (Fig. 1). There was no detectable peak in the chromatograms from the other coral extracts, indicating that carotenoid levels were very low or zero in those coral extracts. However, we could not reach a conclusion as to whether these species possessed symbiont algae with no carotenoids or did not possess symbiont algae at all. Among 25 coral species in this study, S. gracillimun, Dendronephthya gigantea, D. putteri, and D. suensoni are known to be dominant species in the seas off Jeju Island and an artificial propagation study has been attempted with them to preserve coral species (Kim et al., 2004; Choi and Song, 2007). Among these four species, carotenoid peaks were detected only in S. gracillimun. However, no investigation about the pigments or symbiont algae has been reported with these Korean indigenous coral species to date.

The potential carotenoids were marked with numbers in each

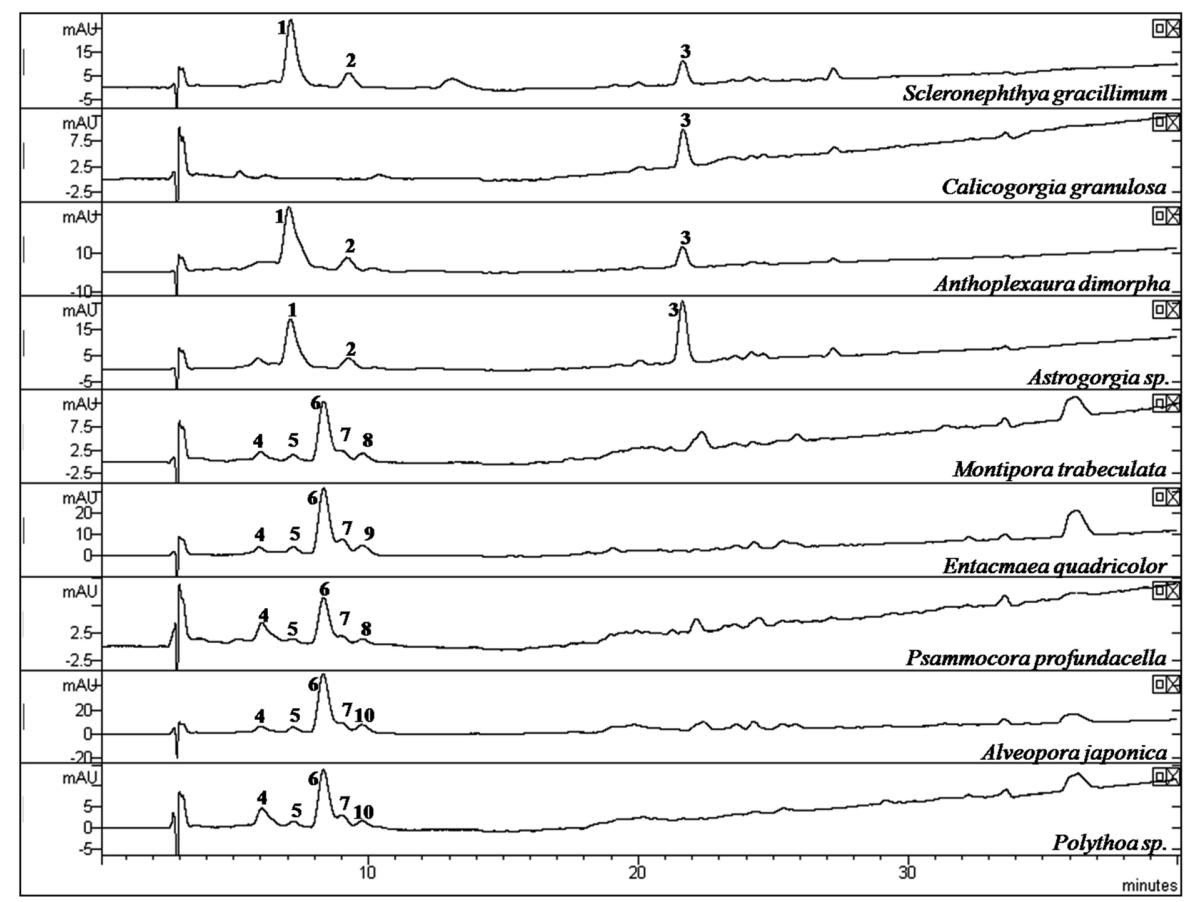

Fig. 1 HPLC chromatograms of carotenoid-containing coral extracts. Among 25 Korean indigenous coral species, nine species showed significant peaks at $450 \mathrm{~nm}$. The presumed carotenoid peaks were determined by UV/visible spectrum at $210-750 \mathrm{~nm}$ and numbered. 




Fig. 2 UV/visible spectra of the presumed carotenoids in indigenous Korean coral extracts. The UV/visible spectra were obtained at 210-700 nm by photodiode array detector from the HPLC. The peak numbers indicate the presumed carotenoids in the HPLC chromatograms in Fig. 1.

Table 2 Mass data of carotenoids from indigenous Korean coral extracts

\begin{tabular}{ccccccccccc}
\hline Peak number $^{1)}$ & 1 & 2 & 3 & 4 & 5 & 6 & 7 & 8 & 9 & 10 \\
\hline Mass fragment $^{2)}$ & 503.5 & 455.6 & 597.6 & 319.4 & 345.5 & 553.6 & 284.4 & 341.5 & 443.4 & 611.7 \\
T. I. ${ }^{3)}$ & n.i. ${ }^{4)}$ & n.i. & n.i. & n.i. & n.i. & peridinin & n.i. & n.i. & n.i. & n.i. \\
\hline
\end{tabular}

${ }^{1)}$ Presumed carotenoid peaks in the HPLC chromatograms in Fig. 1.

${ }^{2)}$ Mass data indicate the fragment ion of each carotenoid with $100 \%$ abundance from LC/APCI-MS.

${ }^{3)}$ T. I.: tentative identification.

4) n.i.: not identified.

chromatogram in Fig. 1 (peaks 1-10). The first clue for the identification of carotenoids was their UV/visible absorption spectra at $210-750 \mathrm{~nm}$. Most carotenoids demonstrate distinguishable $\mathrm{UV} /$ visible spectra, with the wavelength of maximum absorption $\left(\lambda_{\max }\right)$ around $450 \mathrm{~nm}$ (Rodriguez-Amaya and Kimura, 2004). Some common food carotenoids can be identified only by characteristics of UV/visible absorption data, including $\lambda_{\max }$, and the ratio of absorption peak height (Rodriguez-Amaya and Kimura, 2004). The UV/visible absorption spectra at 210-750 nm of the 10 potential carotenoid peaks in Fig. 1 are shown in Fig. 2. The spectra showed in close agreement with the characteristics of carotenoid-specific spectra. However, there was no spectrum corresponding to common food carotenoids, such as $\beta$-carotene, lutein, zeaxanthin, or $\beta$-cryptoxanthin, which show two or three $\lambda_{\max }$ peaks around $450 \mathrm{~nm}$ (Rodriguez-Amaya and Kimura, 2004). Thus, the carotenoids in Korean indigenous coral extracts did not apparently belong to carotenoids common in food.

To identify the carotenoids, MS data of the carotenoid peaks in the HPLC chromatograms were acquired from $m / z$ 200-1000 with a positive APCI ion source. The mass fragments of ions with $100 \%$ abundance are illustrated in Table 2. Identifications were made primarily by comparison with literature data on coral carotenoids. Unfortunately, we could identify only one carotenoid, peridinin (peak 6), which shows mass fragments of $\mathrm{m} / \mathrm{z} 631,613$, and 553, corresponding to $[\mathrm{M}+\mathrm{H}]^{+}\left(6 \%\right.$ abundancy), $\left[\mathrm{M}+\mathrm{HH}_{2} \mathrm{O}\right]^{+}$ (34\% abundancy), and $\left[\mathrm{M}+\mathrm{HH}_{2} \mathrm{OAcOH}\right]^{+}(100 \%$ abundancy), respectively (Maoka et al., 2002). The chemical structure of peridinin and its mass data are presented in Fig. 3. Peridinin was discovered in five coral species, M. trabeculata, E. quadricolor, $P$. profundacella, A. japonica, and Palythoa sp., as a major carotenoid (Fig. 1) and its relative content in each extract showed six times difference among these coral species as shown in Fig. 4. Peridinin has already been reported as a major carotenoid of several coral species, along with diadinoxanthin, diatoxanthin, and pyrrohoxanthin (Ambarsari et al., 1997; Maoka et al., 2011). Peridinin contents determined by spectrophotometrical measurement following relative quantification by HPLC area were ranged from $0.24-0.43 \mathrm{mg} / 100 \mathrm{~g}$ sample in three Acropora corals (Maoka et al., 2011). In the present study, however, exact quantification analysis based on pure compound could not be carried out due to the absence of pure peridinin. Further study is needed for exact determination of peridinin content. Meanwhile, peridinin is also considered a diagnostic pigment for dinoflagellates and high concentrations of this light-harvesting pigment give zooxanthellae their characteristic golden-brown color (Hochberg et al., 2006). For the other carotenoid peaks (peak 1-5 and 7-10), we could not identify any carotenoid from literature data, based on mass fragments. Recently, Maoka (2011) reviewed carotenoids in marine animals and suggested various metabolites derived from major carotenoids including diatoxanthin, alloxanthin and peridinin. However, we could not match mass data in this study with those metabolites and find any known compounds or mass fragments from literature data. These results suggested that the coral extracts in this study may contain unusual carotenoids other than carotenoid peridinin, diadinoxanthin, diatoxanthin, and $\beta$-carotene that have been found commonly in corals. In fact, an unusual carotenoid, canthaxanthin, was identified in Corallium rubrum as a major carotenoid (Cvejic et al., 2007), and a carotenoid of purple color with unknown 

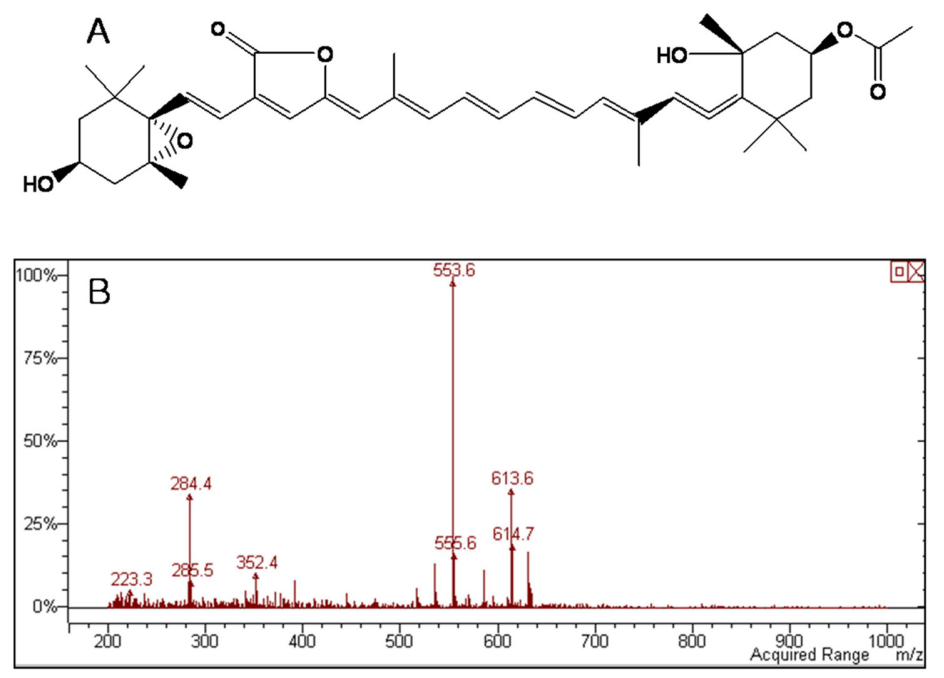

Fig. 3 Chemical structure of peridinin (A) and its mass spectrum (B).

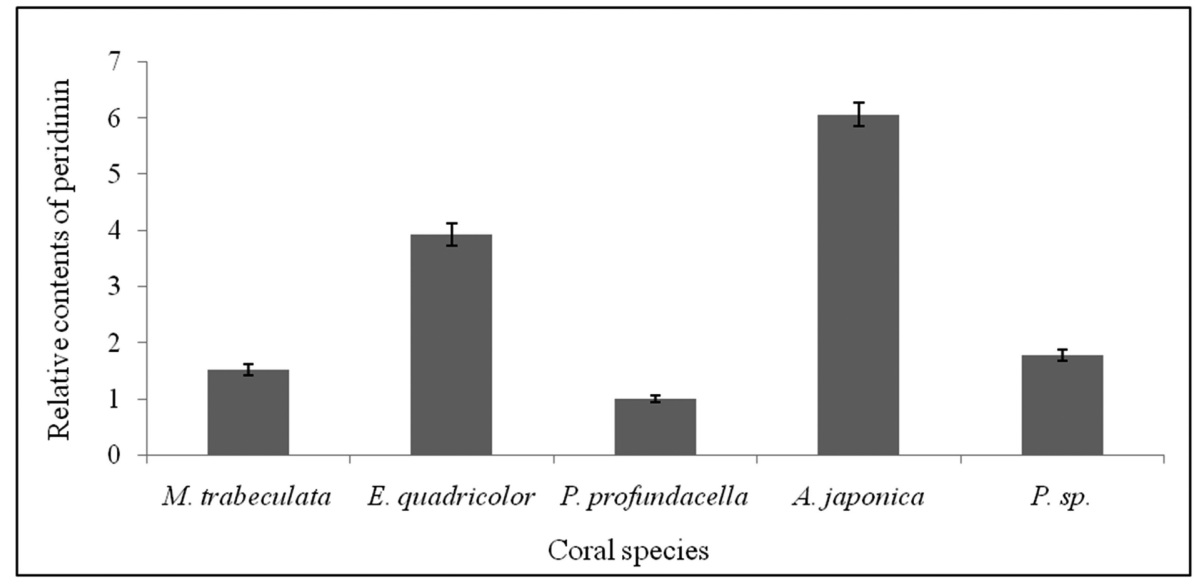

Fig. 4 Relative contents of perinidin in five coral extracts from M. trabeculata, E. quadricolor, P. profundacella, A. japonica, and Palythoa sp., which contain peridinin as a major corotenoid. The HPLC area of perinidin peak in the chromatogram was obtained at $445 \mathrm{~nm}$ and the relative contents of perinidin in each extract were expressed based on the peak area of $P$. profundacella.

chemical structure has been reported in Gorgonia ventalina (Leverette et al., 2008). In the investigation of photosynthetic pigments in corals collected from seas off the coast of Japan, 20 species of corals were analyzed by HPLC and 31 pigment types, including various chlorophylls, were identified (Daigo et al., 2008). However, there was no overlap in the coral species with those in this study, indicating that coral communities and their symbiont algae show great diversity, and that the chemical constituents in coral extracts, therefore, may also be diverse, depending on the coral and algal community.

In summary, carotenoids were examined in 25 coral species collected from Jeju Island, Korea. To our knowledge, this is the first report on a carotenoid analysis of indigenous Korean corals. Of the 25 species examined, only nine were shown to possess putative carotenoids and only peridinin was identified by mass spectrometric analyses. Because corals are among the largest and most diverse ecological communities on the planet and have direct and indirect influences on marine organisms, understanding coral biology and their symbiotic relationship with zooxanthellae is important for the preservation of coral ecosystems. To date, research on indigenous Korean corals has been limited to the taxonomy and reproduction of corals and is still in its infancy compared with the world standard. Thus, further research should be focused on aspects of the coral ecosystem, such as the relationship between pigments and bleaching, the major zooxanthellae living in indigenous Korean corals, and photosynthesis effects on coral growth, beginning with the current results.

Acknowledgments This study was supported by a Korea Institute of Science and Technology (KIST) Gangneung Institute intramural research grant (2Z03850) and by a grant from Marine Biotechnology Program Funded by Ministry of Land, Transport and Maritime Affairs of Korean Government. 


\section{References}

Ambarsari I, Brown BE, Barlow RG, Britton G, and Cummings D (1997) Fluctuations in algal chlorophyll and carotenoid pigments during solar bleaching in the coral Goniastrea aspera at Phuket, Thailand. Mar Ecol Prog Ser 159, 303-7.

Apprill AM, Ridigare RR, and Gates RD (2007) Visible healthy corals exhibit variable pigment concentrations and symbiont phenotypes. Coral Reefs 26, 387-97.

Bae BH, Im KS, Choi WC, Hong J, Lee CO, Choi JS et al. (2000) New acetylenic compounds from the stony coral Montipora sp. J Nat Prod 63 , 1151-514.

Choi EJ and Song JI (2007) Reproductive Biology of the temperate soft coral Dendronephthya suensoni (Alcyonacea: Nephtheidae). Integra Biosciences 11, 215-25.

Cvejic J, Tambutté S, Lotto S, Mikov M, Slacanin I, and Allemand D (2007) Determination of canthaxanthin in the red coral (Corallium rubrum) from Marseille by HPLC combined with UV and MS detection. Mar Biol 152, 855-62.

Daigo K, Nakano Y, Casareto BE, Suzuki Y, and Shioi Y (2008) Highperformance liquid chromatographic analysis of photosynthetic pigments in corals: an existence of a variety of epizoic, endozoic, and endolithic algae. International Coral Reef Symposium (ICRS) Proceedings 11, 123 7. (http://www.reefbase.org/resource_center/publication/icrs.aspx)

Hochberg EJ, Apprill AM, Atkinson MJ, and Bidigare RR (2006) Bio-optical modeling of photosynthetic pigments in corals. Coral Reefs 25, 99-109.

Kang DH, Song JI, and Choi KS (2005) Image analysis of typhoon impacts on soft coral community at Munseom in Jeju, Korea. Ocean Polar Res 27, 25-34.

Kim SH, Lee J, Kim YT, Kim HC, Yang YS, Suh SJ et al. (2004) Artificial propagation and application on the Korean soft corals. Underwater Sci Technol 5, 17-24.
Kim SM, Jung YJ, Kwon ON, Cha KH, Um BH, Chung D et al. (2012) A potential commercial source of fucoxanthin extracted from the microalga Phaeodactylum tricornutum. Appl Biochem Biotechnol 166, 1843-55.

Leverette CL, Warren M, Smith MA, and Smith GW (2008) Determination of carotenoid as the purple pigment in Gorgonia ventalina sclerites using Raman microscopy. Spectrochim A 69, 1058-61.

Maoka T (2011) Carotenoids in marine animals. Mar drugs 9, 278-93.

Maoka T, Akimoto N, Tsushima M, Komemushi S, Mezaki T, Iwase F et al. (2011) Carotenoids in marine invertebrates living along the Kuroshio current coast. Mar Drugs 9, 1419-27.

Maoka T, Fujiwara Y, Hashimoto K, and Akimoto N (2002) Rapid identification of carotenoids in a combination of liquid chromatography/ UV-visible absorption spectrometry by photodiode-array detector and atmospheric pressure chemical ionization mass spectrometry (LC/PAD/ APCI-MS). J Oleo Sci 51, 1-9.

Mydlarz LM, McGinty ES, and Harvell CD (2010) What are the physiological and immunological responses of coral to climate warming and disease? J Exp Biol 213, 934-45.

Osinga R, Schutter M, Griffioen B, Wijffels RH, Verreth JAJ, Shafir S et al. (2011) The biology and economics of coral growth. Mar Biotechnol 13, $658-71$.

Rodriguez-Amaya DB, and Kimura M (2004) HarvestPlus Handbook for Carotenoid Analysis, In HarvestPlus Technical Monograph (Vol. 2), HarvestPlus, Washington, USA.

Seo Y, Rho JR, Geum N, Yoon JB, and Shin J (1996) Isolation of guaianoid pigments from the gorgonian Calicogorgia granulose. J Nat Prod 59, 985-6.

Song JI and Lee IS (1998) Fauna of anthozoans from adjacent waters of Geojedo Island in Korea. Korean J Syst Zool 14, 229-42.

Venn AA, Wilson MA, Trapido-Rosenthal HG, Keely BJ, and Douglas AE (2006) The impact of coral bleaching on the pigment profile of the symbiotic alga, Symbiodinium. Plant Cell Environ 29, 2133-42. 